\title{
Bacia Cicloviária - uma proposta metodológica para a implantação da mobilidade ciclística em Florianópolis, SC, \\ Brasil
}

\author{
Bacia Ciclo viaria - una propuesta metodológica para la \\ implantación de la movilidad ciclística en Florianópolis, SC, \\ Brasil
}

\section{Cycling Basin - a methodological proposal for the implantation of cycling mobility in Florianópolis, SC, Brazil}

\author{
Roberta Raquel \\ betaraquel@gmail.com \\ Universidade Federal de Santa Catarina, UFSC, Florianópolis, SC
}

\begin{abstract}
Resumo: A mobilidade urbana tornou-se uma questão central para o futuro das cidades e a bicicleta mostra-se como um novo paradigma de mobilidade, já que seus benefícios incorporam desde a perspectiva ambiental à socioespacial. Entretanto, é necessário garantir que a mesma possa ser utilizada de forma segura. Assim, a partir de uma análise bibliográfica e considerando importantes indicadores para a ciclomobilidade, este trabalho apresenta um modelo conceitual de Bacia Cicloviária como um instrumento metodológico para implantação do sistema cicloviário na cidade insular de Florianópolis.
\end{abstract}

Palavras-Chave: Mobilidade Urbana; Cidade Insular; Ciclismo.

Resumen: La movilidad urbana se ha convertido en un tema central para el futuro de las ciudades y la bicicleta se muestra como un nuevo paradigma de la movilidad, ya que sus beneficios incorporan desde la perspectiva ambiental hasta la social y espacial. Sin embargo, debe asegurarse de que se puede utilizar con seguridad. Por lo tanto, a partir de una revisión de la literatura y teniendo en cuenta los indicadores importantes para el ciclo movilidad, este artículo presenta un modelo conceptual de Bacia Ciclo viaria como herramienta metodológica para la implementación del sistema ciclo viario en la Isla de Florianópolis, Santa Catarina, sur de Brasil.

Palabras clave: Movilidad urbana; Ciudad insular; Ciclismo.

Abstract: Urban mobility has become a central issue for the future of cities and the bicycle arises as a new paradigm of mobility, once its benefits incorporate environmental as well as socio-spatial perspectives. However, it is necessary to ensure its use safely. Thus, based on a bibliographical analysis and considering important indicators for cyclo-mobility, this paper aims to present the conceptual model of the Cycling Basin as a methodological instrument for implantation of the cycle system in the island city of Florianópolis, Santa Catarina State, Southern Brazil.

Keywords: Urban Mobility; Island City; biking. 


\section{INTRODUÇÃO}

A mobilidade urbana tornou-se uma questão central para pensar as cidades. Os efeitos sobre o ambiente urbano não atingem apenas os grandes centros, as cidades médias também passaram a sofrer, nos últimos anos, com o atual modelo de mobilidade - calcado no uso do transporte individual motorizado. A geografia, assim como outras áreas do conhecimento, vem se debruçando sobre essa temática, mas pouco se discute a respeito da mobilidade ativa - a pé e bicicleta.

São inúmeros os benefícios da bicicleta como meio de transporte cotidiano, desde a perspectiva ambiental até a social e espacial. Por isto, é regulada pela Política Nacional de Mobilidade Urbana - PNMU (BRASIL, 2012), que estabelece princípios, diretrizes, objetivos e instrumentos para a mobilidade urbana nas esferas federal, estadual e municipal. A PNMU prioriza o transporte coletivo e a mobilidade ativa sobre o individual motorizado, entretanto, a despeito do rege a Lei, ainda são os automóveis que mais recebem atenção nas cidades brasileiras, através do alargamento de vias, construção de novos viadutos, pontes, túneis e áreas de estacionamento.

O uso da bicicleta em cidades europeias é uma realidade constituída. Embora não seja unanimidade no continente (VALE, 2016), ela chega a representar um terço dos deslocamentos no norte da Europa. Para Vale (2016, p. 46), "a bicicleta é provavelmente o meio de transporte mais eficaz e racional para os deslocamentos urbanos, além dos deslocamentos a pé".

Ainda que estejamos longe desse cenário, é possível encontrar vários exemplos de uso da bicicleta nas capitais brasileiras (SOARES et al., 2015), também em cidades pequenas (SOARES, GUTH, 2018). E, embora a média dos deslocamentos por bicicleta no Brasil em 2014 corresponda a apenas 2,6\%, de acordo com ANTP $(2016)^{1}$, ela pode chegar a 15\%, como demonstra a pesquisa de origem e destino ${ }^{2}$ da Baixada Santista.

Diante desse contexto e, a partir da realidade de Florianópolis, o objetivo desse artigo é apresentar a Bacia Cicloviária como um instrumento metodológico capaz de auxiliar no processo de implantação e aprimoramento da mobilidade ciclística em cidades médias.

A primeira vez que o conceito de Bacia Cicloviária é mencionado, com Sérgio Luiz Bianco (2009), surge como termo emprestado do conceito geográfico de bacia hidrográfica, e foi definida como área de abrangência contida dentro dos limites em que um sistema cicloviário deixa de ser interessante para um ciclista, seja pela distância, seja por um limite físico. A partir dessa leitura, o conceito foi desenvolvido por Raquel (2010) e aplicado como modelo conceitual pela ViaCiclo - Associação dos Ciclousuários da Grande Florianópolis (2010) na cidade de Florianópolis.

1 Os relatórios 2015 e 2016 da ANTP podem ser encontrados, respectivamente, em: http://files.antp.org.br/simob/simob2015-v6.pdf e http:/ / files.antp.org.br/simob/simob-2016-v6.pdf, ambos indicam que a média de deslocamento por bicicleta no Brasil é de $2 \%$. Porém, decidimos citar os dados do relatório que faz uma análise comparativa do período de 2003 a 2014 , pois entendemos que há maior consistência ao realizar essa análise de forma histórica.

2 Pesquisa realizada pela Empresa Municipal de Transporte Urbano (EMTU), ver em: http://www.saopaulo.sp.gov.br/ spnoticias/ultimas-noticias/46-da-populacao-da-baixada-anda-a-pe-ou-de-bicicleta/. 
Recuperar o conceito e ampliar sua análise é uma forma de incorporar aos estudos urbanos um outro referencial de mobilidade. $\mathrm{O}$ uso da bicicleta traz novas perguntas, novos enfoques teóricos e metodológicos, aspectos fundamentais para pensar as cidades.

\section{O LUGAR BICICLETA NO CAMPO TEÓRICO METODOLÓGICO}

A presença da bicicleta como tema de pesquisa científica vem crescendo, porém, ainda é incipiente para a geografia. A fim de conhecer o cenário geográfico da produção científica sobre o tema, realizou-se um levantamento nas principais revistas brasileiras Qualis A1 e A2 que constam na plataforma Sucupira. Porém, ao buscar pelas palavras-chaves "bicicleta" e "mobilidade ciclística" tanto no título quanto nos resumos dos trabalhos, não foi possível encontrar nenhum trabalho. Já na plataforma Scielo, uma biblioteca eletrônica com uma coleção ampla de periódicos científicos, muito utilizada por acadêmicos, encontramos 230 artigos com 'bicicleta' e um com 'mobilidade ciclística'. Na sua esmagadora maioria, os trabalhos foram desenvolvidos na área da saúde. Ao aplicar o filtro para trabalhos ligados à área da geografia identificou-se apenas quatro, ou seja, apenas 1,7\% dos trabalhos dispostos na plataforma sobre o uso da bicicleta nas cidades estão em revistas geográficas.

Desses trabalhos de cunho geográfico, dois correspondem a resenhas de livros: Alvarez (2012) faz um breve relato sobre o livro Ciclovista Guadalajara: descubrir la ciudad en Bicicleta, de Eugenia Coppel Ochoa, no qual é possível, através de fotografias, vivenciar a experiência da autora usando bicicleta na cidade e fazendo quase o papel de guia de rotas e itinerários; Albuerne (2016) resenha o livro Bicicletas para la ciudad: una propuesta metodológica para el diagnóstico y la planeación de infraestructura ciclista, de Manuel Suárez Lastra, Carlos Galindo-Pérez e Masanori Murata, que propõe realizar tanto um apanhado teórico sobre o uso da bicicleta quanto uma análise da rede cicloviária e dos programas governamentais da Cidade do México. O terceiro, trata-se de um artigo de Vale (2016) que, a partir de dados europeus sobre o uso da bicicleta, faz uma análise dos fatores que contribuem para a promoção da utilização da bicicleta no espaço urbano. Por fim, o artigo de Ribeiro (2018) faz uma reflexão sobre exclusão social-espacial através da distribuição espacial de bicicletas compartilhadas, ciclovias, bicicletários e serviços de suporte a pessoas que usam a bicicleta como transporte ou lazer no município do Rio de Janeiro.

Além dos artigos científicos, também buscamos outras modalidades de trabalhos acadêmicos, através do Catálogo de Teses e Dissertações da CAPES. Foi possível identificar 9.916 trabalhos com a palavra-chave "mobilidade ciclística", sendo que destes, 604 estão na área de conhecimento geográfico; os trabalhos com termo "bicicleta" correspondem a 518 , sendo 16 na geografia.

Dessa forma, é possível observar que nos trabalhos acadêmicos - dissertações e teses - a bicicleta tem maior presença, entretanto, o baixo número de artigos científicos em revistas geográficas reflete diretamente sobre a produção do conhecimento da temática e, ao nosso ver, coloca em questão o caráter crítico que a geografia tem a respeito dos fenômenos urbanos. Entendemos que é preciso pensar a mobilidade a partir de outra 
perspectiva, pois não podemos manter nossas análises condicionadas à 'automovelcracia' ${ }^{3}$. Nesse sentido, a bicicleta se apresenta não apenas como um modo de transporte capaz de ampliar a qualidade da mobilidade urbana, mas também como agente político da sociabilidade urbana.

\section{A BICICLETA NA CONTRAMÃO}

Diante dos inúmeros efeitos indesejados do uso do automóvel nas cidades e do caráter estruturante que a mobilidade exerce no ordenamento territorial, bem como suas implicações para o uso e apropriação do espaço público, é inconcebível pensar uma cidade sem a presença da bicicleta. Seu uso promove desde benefícios individuais - como saúde, economia e autonomia - a benefícios coletivos, como redução da poluição do ar e sonora, redução de gastos públicos e ampliação do espaço público.

O baixo custo de aquisição da bicicleta, assim como de sua manutenção, permite que os gastos familiares com transporte sejam reduzidos. De acordo com o IBGE (2010), o transporte é o terceiro maior gasto familiar, atrás apenas dos gastos com a alimentação. Estes gastos são ainda maiores, segundo o IPEA (2012), entre os usuários de transporte privado. Mas é sobre a vida dos mais pobres que os custos com o transporte têm maiores efeitos; as altas tarifas do transporte público, por exemplo, restringem as oportunidades de trabalho dos mais pobres, muitas vezes os impossibilitando inclusive de buscá-lo (IPEA, 2003).

A saúde é outra dimensão em que o uso da bicicleta tem impactado de forma positiva a vida das pessoas. A falta de atividades físicas, por falta de tempo ou condições financeiras, é uma realidade presente no cotidiano da população urbana, principalmente a de baixa renda. Conforme Carvalho e Freitas (2012, p. 1618), “rotinas sedentárias que provocam diversas doenças crônicas, como o diabetes tipo 3, doenças coronarianas e a obesidade infantil, têm estimulado a busca do ciclismo como uma das alternativas para o transporte urbano". Lima et al. (2017) afirmam que estratégias que promovem o aumento do tempo de atividade física por meio da mobilidade ativa vêm recebendo atenção mundial, tendo em vista sua importância para a prevenção de doenças.

Entretanto, é preciso garantir que seu uso possa ser realizado de forma segura. Nesse sentido, é imprescindível que haja infraestrutura adequada e que políticas públicas voltadas a mobilidade ativa sejam implementadas. E, embora muito se fale sobre distâncias percorridas, pouco se sabe sobre elas, sendo raro encontrar pesquisas que analisem as relações entre distância e tempo gasto nos deslocamentos. Na sua grande maioria, o tempo é o único elemento considerado, mas a distância pode nos falar muito sobre o deslocamento. A exemplo do que demonstra o Diário do Transporte ${ }^{4}$, a distância média das viagens na

3 Eduardo Galeano usou o termo em 1996 em artigo publicado na Revista Atenção, n. 4. Nele, o autor discute como o automóvel está ligado a um modelo de consumo baseado no modelo de desenvolvimento dos Estados Unidos, o que gera uma série de problemas sociais, como a dependência do petróleo e das empresas que dominam o negócio do transporte, além das inúmeras mortes no trânsito.

4 https://diariodotransporte.com.br/2016/12/13/paulistanos-fazem-muitas-baldeacoes-andam-bastante-para-chegar-asestacoes-ou-pontos-e-esperam-bastante-os-onibus-e-trens/. 
cidade de São Paulo é de 7,8 km, entretanto o tempo de deslocamento realizado pelo transporte público pode ultrapassar 90 minutos. Considera-se que, de acordo o Instituto de Energia e Ambiente (2010), as bicicletas são mais eficientes em distâncias de até $5 \mathrm{~km}$, como demonstra a Figura 1, mas com a prática, o ciclista tende a utilizar a bicicleta para viagens mais longas, superando o automóvel quando há congestionamentos.

Figura 1: Tempo médio de deslocamento em diferentes modalidades

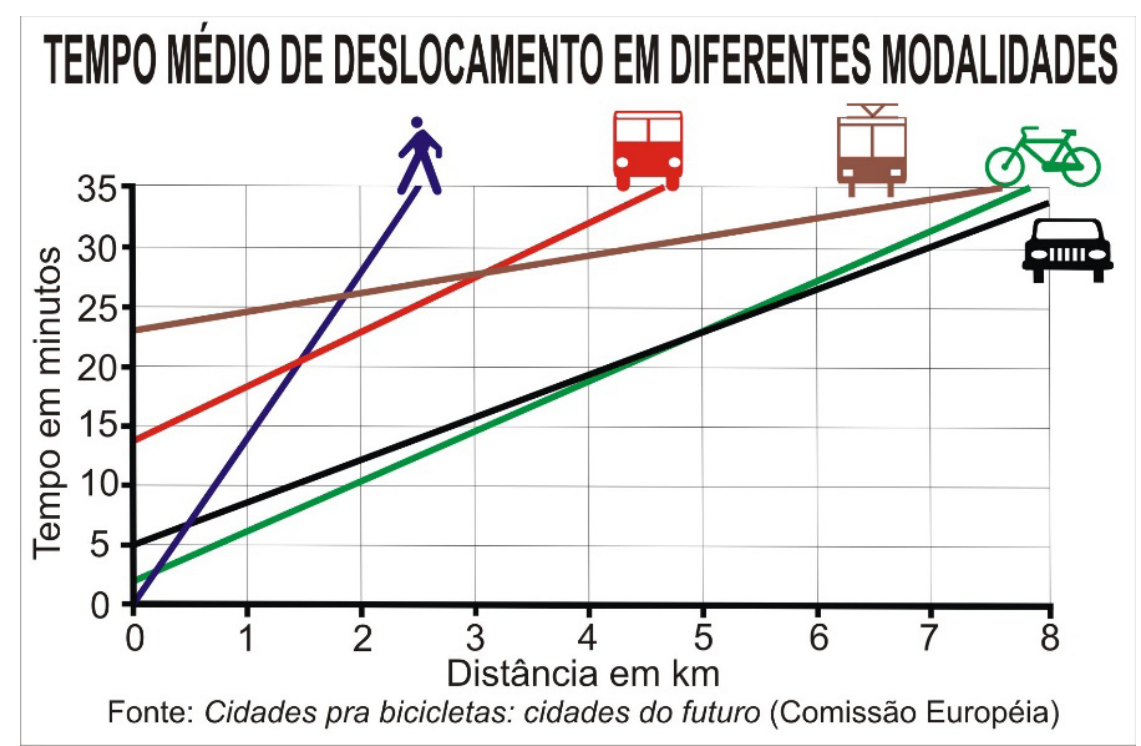

É importante ressaltar que o conceito de eficiência não está atrelado apenas à velocidade ou à rapidez, mas a diferentes aspectos, como ambiental, energético e de ocupação espacial. Entretanto, há de se destacar que é mais rápido deslocar-se em bicicleta em horários de maior congestionamento, como demonstram os Desafios Intermodais ${ }^{5}$.

Ainda que seja o automóvel o veículo associado à autonomia, é a bicicleta que se apresenta com mais força tal característica. Para Gorz (2005), ao contrário do ciclista, o motorista é dependente de uma matriz energética que o transforma em consumidor e usuário de serviços, enquanto a bicicleta tem a liberdade do movimento dos seus corpos para seus deslocamentos. Ademais, o deslocamento em bicicleta está livre de congestionamentos e da busca por estacionamentos. "A dependência, em relação ao motor, nega a uma coletividade exatamente aqueles valores que se considerariam implícitos ao melhoramento da circulação" (ILLICH, 2005, p.43). Ter o controle de sua própria velocidade sem impedir o deslocamento dos demais ou sem colocar vidas em risco, é também uma maneira de contribuir com a coletividade.

Entre as externalidades do automóvel, está a poluição. E, sem dúvida, é um grave problema nos centros urbanos, visível, muitas vezes, a olho nu e sentida na 'pele'. Os efeitos da poluição, além de incidirem sobre a saúde da população, também se refletem

5 Competição com fins pedagógicos, geralmente organizada por organizações de ciclistas, na qual os competidores, cada um usando um meio de mobilidade diferente, deve sair de um mesmo ponto A até um mesmo ponto B. A competição demonstra não apenas o tempo de deslocamento, mas também indicadores como poluição e custo para saber mais consulte Stinghen e Pace (2010). 
nos gastos públicos (LEANDRO; ANGEOLETTO, 2017; RUMBLE et al., 2019). E, de acordo com Breithaupt (2011), os transportes são responsáveis por aproximadamente metade das emissões de $\mathrm{CO}_{2}$, sendo $90 \%$ proveniente do transporte rodoviário. Segundo Braga et al. (2001), episódios de poluição excessiva aumentaram o número de mortes nos centros urbanos. Para o autor, resolver esse problema "demanda disposição da autoridade pública em priorizar a saúde e coragem para enfrentar todos os elos da cadeia geradora de poluição, desde o dono da indústria de automóveis até o proprietário do veículo" (BRAGA; PEREIRA, 2001 p. 70).

Porém, entre as gestões públicas é mais comum que medidas paliativas sejam adotadas, como o rodízio de veículos - restrição de circulação de veículos em determinados dias da semana e horários, o cronograma das restrições é organizado pelo número de placas. De acordo com Souza (2013), a cidade de São Paulo adotou o rodízio em 1997 sob o pretexto de diminuir a poluição atmosférica, no entanto muitos paulistanos adquiriram um segundo veículo a fim de circular livremente todos os dias.

Programas que regulamentam e estabelecem limites para emissões de poluentes provenientes da queima da gasolina e diesel são observados em grandes centros econômicos como Estados Unidos, Japão e na União Europeia, porém tais medidas não extrapolam suas fronteiras. Países da América Latina, a exemplo da Guatemala, funcionam como quintal da 'desova' de veículos que não podem mais circular nos EUA'.

Além da poluição do ar, o som ao redor é uma constante em nossas vidas. Foi inclusive tema e título de um dos filmes de Kleber Mendonça e, assim como na obra cinematográfica, os ruídos comandam o ritmo das cidades. Em meio a tantos sons podemos afirmar que os automotores se destacam entre eles - o acelerar, o frear, o buzinar são alguns dos ruídos indesejáveis que nossos ouvidos estão 'acostumados. Cohen e Castillo (2017) afirmam que o ruído ambiental é um dos principais elementos de contaminação das cidades modernas, sendo os veículos automotores os principais responsáveis. A regeneração do espaço público e áreas verdes são elementos que, integrados com a mediação do ruído ambiental, pode ajudar a determinar onde, porque, como e quando é possível gerar uma política de mobilidade que favoreça o uso da bicicleta e andar a pé para diminuir o uso do automóvel. Se trata, então, de construir uma nova gestão integral sobre o ruído ambiental citadino (COHEN, CASTILLO, 2017, p.70).

Ou seja, para combater uma das principais fontes de poluição sonora do ambiente urbano é preciso implementar políticas de mobilidade que favoreçam o caminhar e o pedalar.

Os efeitos da poluição sonora e do ar juntamente com o número de acidentes têm impacto direto sobre os gastos públicos. O relatório do IPEA (2015) apresenta a estimativa dos custos dos acidentes de trânsito no Brasil no ano de 2014.

Os acidentes de trânsito no Brasil matam cerca de 45 mil pessoas por ano e deixam mais de 300 mil pessoas com lesões graves. Numa estimativa conservadora, observou-se 
que os acidentes em rodovias custam à sociedade brasileira cerca de $\mathrm{R} \$ 40$ bilhões por ano, enquanto os acidentes nas áreas urbanas em torno de R\$ 10 bilhões, sendo que o custo relativo à perda de produção responde pela maior fatia desses valores, seguido pelos custos hospitalares (IPEA, 2015, p. 13).

A perda de produção tem um duplo impacto, pois além da renda da vítima deixar de fazer parte da renda familiar também recai sobre a previdência social. Ademais, o custo público para a manutenção do sistema viário usado pelo transporte individual foi, em 2014, segundo a ANTP (2016), de 9,3 bilhões; em contrapartida, o gasto com o transporte público foi de 2,7 bilhões. O transporte individual, além de receber volume maior de investimentos públicos, tem seu ônus dividido entre toda a sociedade.

Esse modelo de mobilidade também consome mais espaço público, seja com os inúmeros estacionamentos para proteger o patrimônio privado, grande parte deles em áreas públicas, seja com as inúmeras vias cada vez mais largas, desenhadas para tentar dar fluxo aos automóveis. Illich (2005) demonstra de forma bem didática quanto os automóveis consomem de espaço para a circulação nas cidades.

Para que 40 mil pessoas possam cruzar uma ponte em uma hora movendo-se a 25 $\mathrm{km} / \mathrm{h}$, é preciso que ela tenha 138 metros de largura se as pessoas viajam de carro, 38 metros se viajam de ônibus e 20 metros se viajam a pé. Por outro lado, se vão de bicicleta, a ponte necessita ter apenas 10 metros de largura (ILLICH, 2005, p. 63).

A bicicleta, nesse sentido, promove, ao consumir menos espaço público para os deslocamentos, mais espaços de lazer, ócio e convívio, ou seja, importantes formas de constituir a vida urbana - o que só é possível alcançar com o desenvolvimento de políticas públicas de mobilidade, mas integradas a outras políticas públicas, como saúde, uso do solo, meio ambiente e habitação.

Diante do exposto, é possível afirmar que a bicicleta vai na 'contramão' do atual modelo de mobilidade, na medida em que ela rompe com a lógica hegemônica de consumo de energia e de espaço; seu uso não emite poluentes e nem ruídos; e, ao invés de onerar os cofres públicos, ela promove economia do erário, bem como economia familiar. Entendemos, assim, que implementar a bicicleta na mobilidade urbana é fundamental para o futuro das cidades do Brasil.

\section{BACIA CICLOVIÁRIA: A EXPERIÊNCIA DE FLORIANÓPOLIS}

A capital de Santa Catarina, Florianópolis (Fig. 2), possui uma área de 424 km² distribuído em uma porção insular e uma pequena parte continental, com apenas 11,9 km² do território. Separadas pelas baías sul e norte, as pontes Pedro Ivo Campos, Colombo Salles e Hercílio Luz (está desativada desde 1991), são suas únicas conexões (Fig. 3). 
Figura 2 - Mapa de localização do munícipio de Florianópolis, SC.

\section{Mapa de localização do município de Florianópolis - SC}

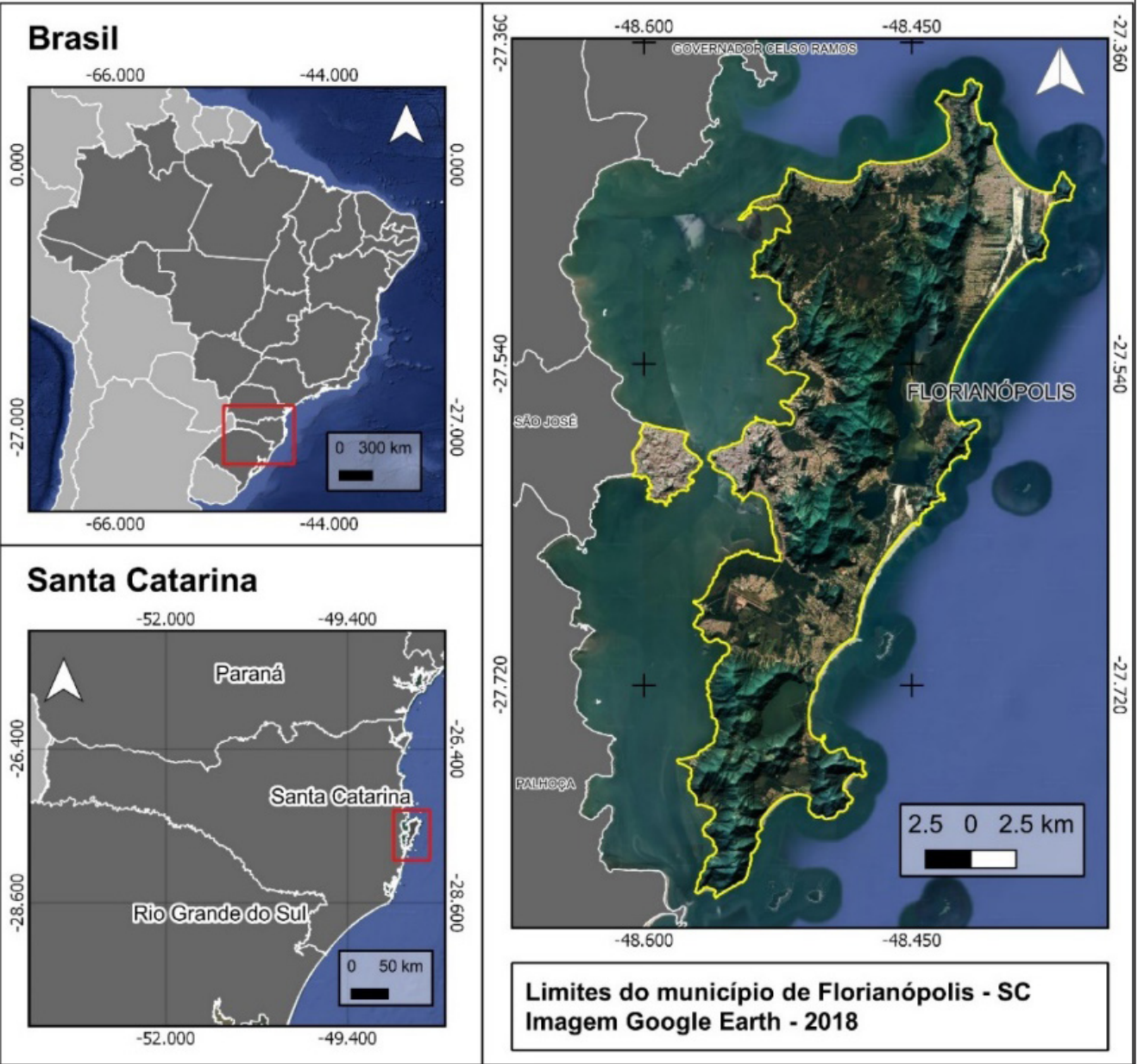

Fonte: T.B. Hoffmann, 2019.

Fig. 3: Pontes Pedro Ivo Campos, Colombo Sales e Hercílio Luz, Florianópolis, SC.

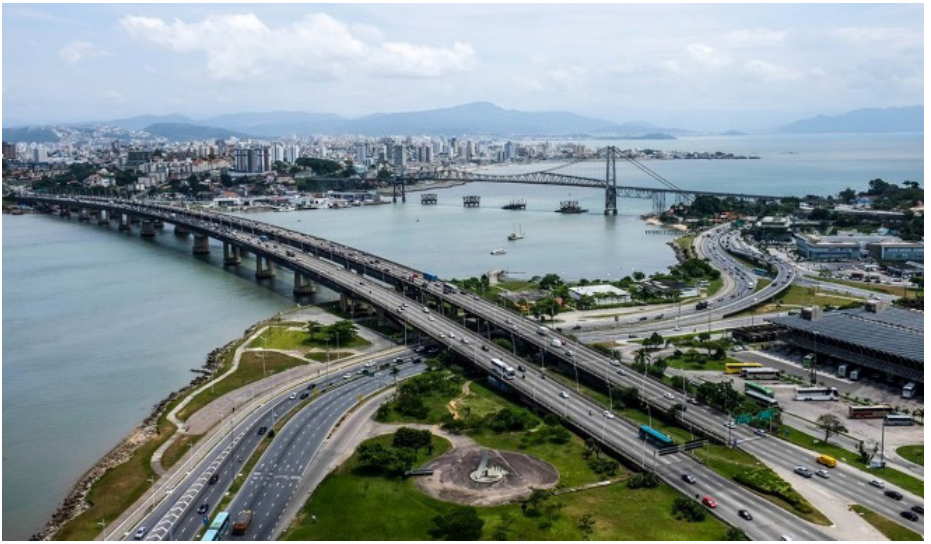

Fonte: Sadowski, $2018^{7}$.

7 SADOWSKI, David. G1 Santa Catarina, Florianópolis passará a contar com guincho gratuito nas pontes. Florianópolis, 21 dez. 2015. Disponível em: http://g1.globo.com/sc/santa-catarina/noticia/2015/12/florianopolis-passara-contar-comguincho-gratuito-nas-pontes.html. Acesso em: dezembro de 2018. 
A temperatura média anual de Florianópolis é de $20,5^{\circ} \mathrm{C}$ e a umidade relativa é de 81\% (WREG et al., 2012). A geomorfologia da cidade é marcada, conforme Covello, Horn Filho e Brilha (2018), por dois domínios fundamentais, o primeiro de morros, montanhas e elevações, e o segundo de planícies costeiras, que interligam essas elevações. A altitude média de Florianópolis é de 290 m, embora chegue até 528 m, porém na região próxima ao mar as altitudes não ultrapassam os $100 \mathrm{~m}$. A cidade conta com 421.240 mil habitantes e tem uma densidade demográfica de 623,68 hab./ $\mathrm{km}^{2}$, segundo o IBGE (2011).

A topografia e as condições climáticas geralmente são vistas como barreiras para a implantação de um planejamento cicloviário; entendemos que elas devem ser consideradas, mas não como impeditivas, e sim a fim de adequar a infraestrutura cicloviária às condições naturais da cidade.

Além disso, a simples configuração topográfica de uma cidade não determina, automaticamente, a sua viabilidade para o ciclismo. A tendência natural é o desenvolvimento do sistema viário em direções que suavizem a declividade da rampa, adotando um traçado de "meia-encosta". Dessa forma, somente sítios urbanos muito acidentados tornam o uso da bicicleta inviável (BRASIL, 2007, p. 62).

Entre as recomendações a respeito da topografia é indicado que quanto maior a extensão da subida, menor deve ser seu declive. Para Vale (2016, p. 48), “de uma forma geral, o declive ideal para o uso da bicicleta será o menor possível, preferencialmente inferior a 3\%", no entanto o autor assume que é possível circular em zonas de maior declive, deste que não tenham grande extensão. Em AASHTO (1999), o grau de declividade pode chegar a 11\% desde que não ultrapasse a distância de 15 metros e que em distâncias acima de 200 metros o grau seja de 5 a $6 \%$.

Nesse sentido, Florianópolis é uma cidade bastante privilegiada, pois embora possua áreas com ampla altitude, a maioria da população reside nas planícies costeiras da Ilha e nos bairros continentais. Ademais, é importante salientar que cerca de $45 \%$ do território de Florianópolis, segundo Covello (2018), está designado como área protegida, grande parte dessas áreas sendo as de maior altitude. No caso de ocupações já consolidadas em encostas, como o Maciço do Morro da Cruz e o Maciço da Costeira, a construção de estacionamentos públicos para bicicletas no sopé dos morros pode se apresentar como uma solução simples.

É possível identificar uma série de soluções e recomendações entre manuais, pesquisas e estudos que tratam sobre a mobilidade ciclística. No Brasil a bicicleta é pauta presente na gestão pública desde o fim da década de 70, como demonstram os manuais da GEIPOT $(1980 ; 1984)$ que tratam sobre o planejamento cicloviário.

Entretanto, sua ausência é evidente no planejamento urbano das cidades, inclusive em Florianópolis. Dessa forma, entende-se que a Bacia Cicloviária se apresenta como um importante instrumento metodológico de auxílio para a implementação do planejamento cicloviário.

A pesquisa, fruto de uma revisão bibliográfica e documental, se deu em duas etapas: a primeira baseou-se na análise de artigos e manuais sobre planejamento cicloviário (ITDP, 2017; BRASIL, 2007; GONDIM, 2010; COMISSÃO EUROPÉIA, 2000) e a segunda 
etapa, considerando a necessidade de conhecer as especificidades socio-históricas da cidade, realizou uma análise das características do processo de ocupação de Florianópolis (CONCEIÇÂO, 2014; VAZ, PEREIRA, 2011; PEDRALLI, DIAS, 2015), além de uma análise de mapas de uso e ocupação do solo e de densidade populacional.

Conhecer o processo de ocupação da capital catarinense foi fundamental para compreender a dinâmica socioespacial dos bairros. Para Conceição (2014), a estrutura de ocupação, ocorrida no século XVIII, está ligado a fatores históricos, socioeconômicos e culturais que induziu uma ocupação territorial polinucleada, isolando a população em pequenos núcleos distantes entre si no interior da ilha. De acordo com Vaz e Pereira (2011) essa formação socioespacial consolidou a cidade como polinucleada, embora, os autores afirmem que a cidade seguiu uma tendência de demais cidades médias brasileiras com o fluxo de deslocamento populacional do interior para a região central, principalmente devido às intervenções viárias. No entanto, é importante ressaltar que a condição polinucleada também está associada com a conformação topográfica da cidade (SILVA et al., 2013).

Essa formação estabeleceu uma vida intensa nos bairros, e é justamente nessa cotidianidade que o uso da bicicleta mostra sua potencialidade. A pesquisa de Lobo, Andrade e Rodrigues (2018), corrobora essa ideia ao demonstrar como o uso da bicicleta em Florianópolis está associado principalmente às compras, seguido de lazer e, depois, trabalho. Em outras cidades, inclusive em grandes centros como São Paulo, a principal motivação de usar bicicleta é o trabalho (IPEA, 2017).

Garantir os deslocamentos da população ao trabalho é tão importante quanto suas demais atividades; dessa forma, conhecer como as pessoas se deslocam pelos bairros e entre eles, conhecer suas necessidades e seus desejos, é imprescindível para pensar e planejar a cidade que queremos. Assim, ao considerar as características topográficas e climáticas de Florianópolis, alinhando aos índices encontrados em manuais, a exemplo do que indica o IDTP (2007) - linearidade, coerência, atratividade, segurança, conforto - e somada as características socioculturais dos bairros, propomos a constituição de 11 Bacias Cicloviárias na capital catarinense (Fig. 4). 
Figura 4: Bacias Cicloviárias em Florianópolis, SC.

\section{Bacias Cicloviárias Florianópolis - SC}

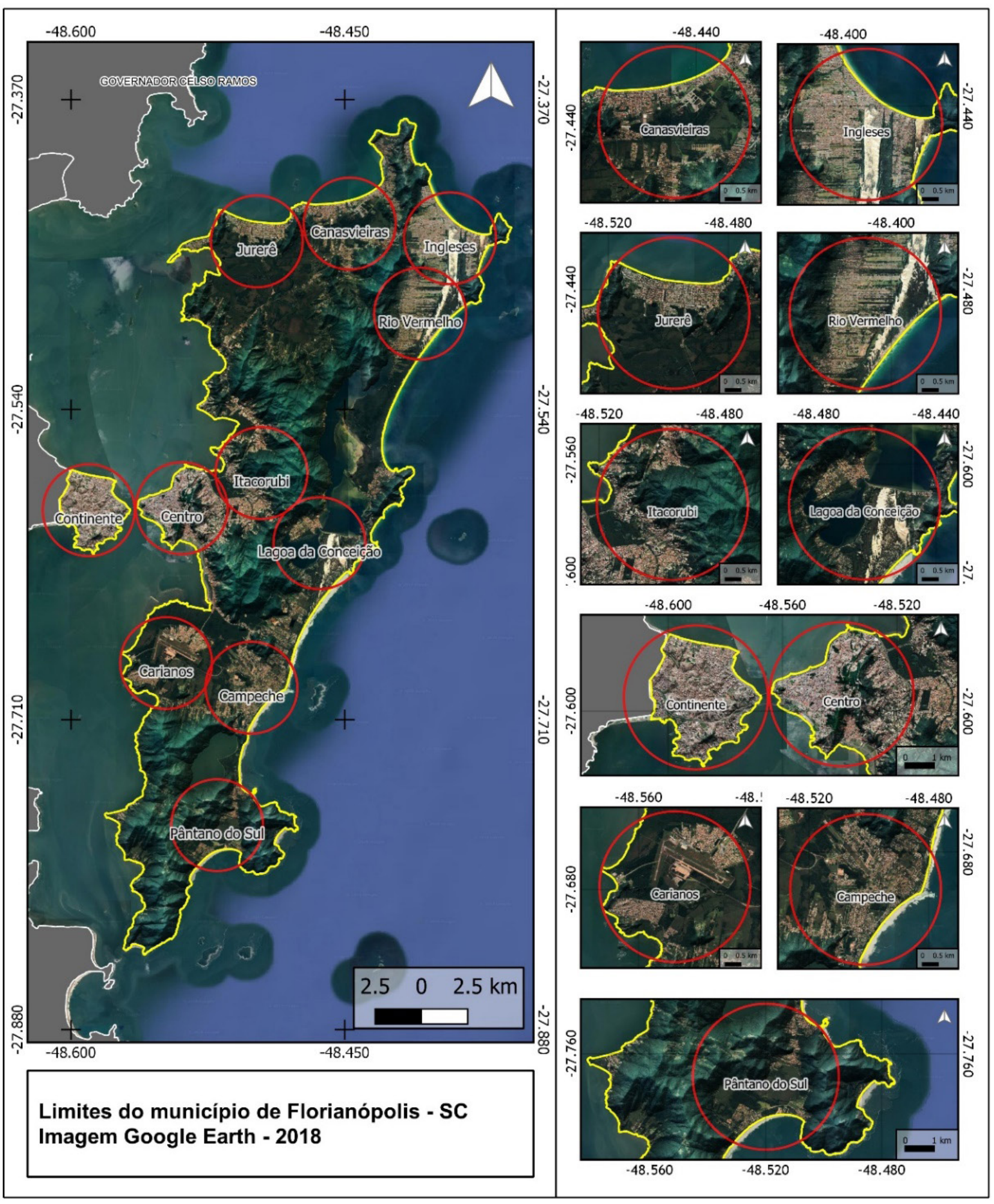

Fonte: T.B. Hoffmann, 2019. 
As circunferências em destaque na Figura 3 correspondem às Bacias Cicloviárias propostas: Centro, Continente, Itacorubi, Campeche, Lagoa da Conceição, Carianos, Pântano do Sul, Jurerê, Canasvieiras, Ingleses e Rio Vermelho. É importante ressaltar que todas as bacias cobrem mais de um bairro. Cada bacia cobre um diâmetro de $5 \mathrm{~km}$, distância em que a bicicleta, como o veículo, se verifica mais eficiente, conforme a Comissão Europeia (2010). Ademais, é possível observar que a distância entre as bacias vizinhas é bastante próxima, em média de $8 \mathrm{~km}$ de deslocamento entre elas, a exemplo das Bacias Centro e Continente, Centro e Itacorubi, Campeche e Carianos e as localizadas na região norte da Ilha, possibilitando, assim, fácil acesso interbairros.

A proximidade das Bacias Centro e Continente é um exemplo especial da necessidade de se instituir um sistema cicloviário integrado em Florianópolis, pois são as bacias com maior adensamento populacional, onde vive $43 \%$ da população, no entanto a única conexão para pedestres e ciclistas se dá por meio de uma passagem sob a ponte Pedro Ivo Campos (Fig. 5).

Embora a cidade tenha um caráter polinucleado, a capital catarinense é também um polo de serviços públicos e comerciais para a região metropolitana, composta por oito municípios, além de Florianópolis - Águas Mornas, Antônio Carlos, Governador Celso Ramos, Santo Amaro da Imperatriz, São Pedro de Alcântara, São José, Biguaçu e Palhoça - provocando diariamente um intenso fluxo de veículos automotores na vias próximas e nas pontes que levam à ilha. Entretanto, a passagem possui uma infraestrutura inadequada, ampliando o sentimento de insegurança tanto de pedestres quanto de ciclistas. Essa insegurança provoca uma demanda reprimida de ciclistas e pedestres e os obriga a enfrentar, seja de ônibus ou carro, os longos congestionamentos para atravessar a ponte.

Figura 5: Travessia de pedestres e ciclistas sob a ponte Pedro Ivo Campos, Florianópolis, SC.

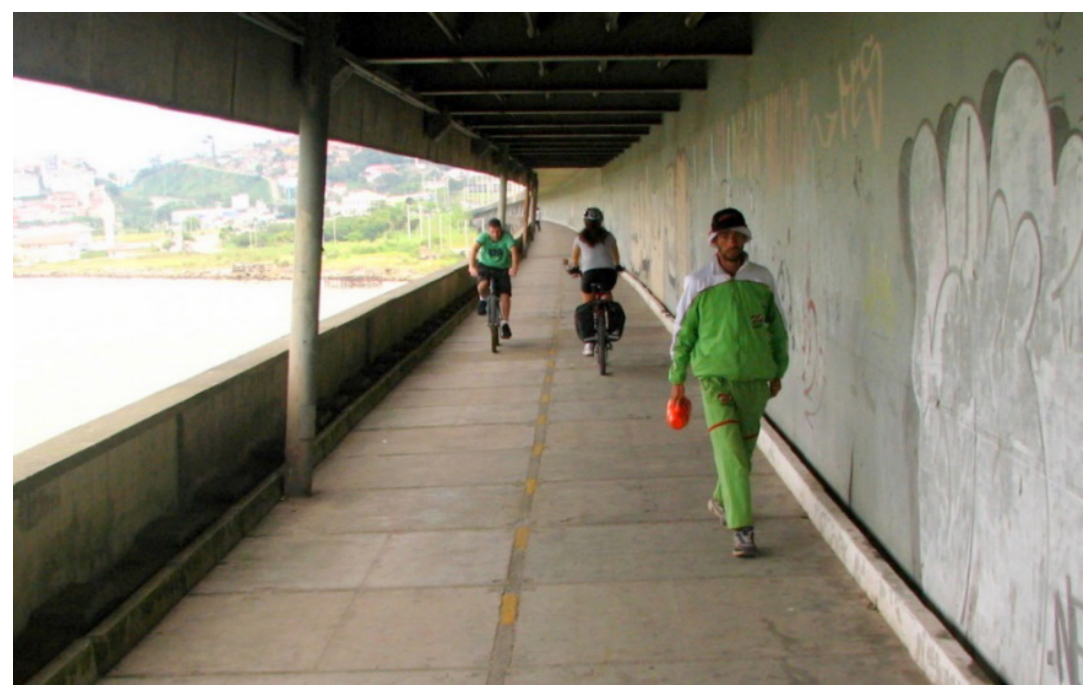

Fotografia: A.G. Soares, 2019.

As regiões sul e norte da Ilha são as mais distantes do centro, atingindo até $40 \mathrm{~km}$ de distância. Para estas o ideal seria que as Bacias Cicloviárias estivessem integradas com 
o sistema de transporte público coletivo, com bicicletários adequados junto aos terminais de ônibus.

A pesquisa realizada pela ViaCiclo demonstra a potencialidade e a viabilidade das Bacias Cicloviárias como um instrumento metodológico para implementação de um sistema cicloviário. A organização aplicou o instrumento em duas bacias cicloviárias - Itacorubi e Campeche - e a partir do estudo sobre os locais, elaborou um relatório ${ }^{8}$ com indicações e projeções de vias necessárias para a mobilidade ciclística.

A Bacia Cicloviária foi desenvolvida a partir das características de Florianópolis, mas é possível, assim como outros modelos, adaptá-la aà realidade de outras cidades. Afinal, criar condições de deslocamento por bicicleta nos bairros e entre eles, através de uma rede de conexão por toda a cidade, além de manter a dinâmica urbana dos próprios bairros, aumenta a sociabilidade, a sustentabilidade e a qualidade de vida dos habitantes por toda a cidade.

\section{CONCLUSÕES}

Mobilidade é mais do que deslocar-se e s formas como as pessoas se movem está diretamente associada à forma como as cidades são vividas e falar sobre vida nas cidades é falar sobre pessoas. Hoje é possível afirmar que os carros são, de certa forma, responsáveis pela morte das grandes cidades. O modelo automotor individual vem ditando, há pouco mais de um século, a pauta do desenho urbano e o que antes era um 'privilégio' das metrópoles passou a ser vivenciado nas médias e pequenas cidades. Mas, afinal, queremos o mesmo futuro dos grandes centros urbanos para as cidades de menor porte? Para pensarmos sobre as cidades que queremos, é necessário pensarmos sobre o modelo de mobilidade que temos.

O futuro das cidades depende de novas medidas, novos modelos de mobilidade. A bicicleta vem, nos últimos anos, mostrando seu potencial como um novo paradigma de mobilidade. Ainda de forma incipiente, mas com muitos exemplos a serem seguidos ou adaptados.

A Bacia Cicloviária se apresenta como uma forma de implementar esse novo modelo na cidade de Florianópolis, que possui sinais de saturação no que diz respeito aos seus deslocamentos por automóveis. Fazer uso da bicicleta, combinada com o transporte público quando for necessário cumprir longas distâncias, ou mesmo por todo o trajeto, é construir um novo modelo de cidade. Quando as pessoas, andando ou pedalando, forem a prioridade, soluções como a Bacia Cicloviária serão implementadas.

É um modelo inicial, precursor na capital catarinense, que deve ser mais bem explorado, porém, trazendo elementos de análise compatíveis com um futuro mais viável para a cidade. Ademais, se mostrou, com a pesquisa desenvolvida pela ViaCiclo, um importante subsídio para o poder público, muitas vezes carente de instrumentos metodológicos.

8 https://www.mobilize.org.br/midias/pesquisas/bacias-cicloviarias.pdf 


\section{REFERÊNCIAS}

ALBUERNE, Adriana L.T. Resenha Bicicletas para la ciudad: Una propuesta metodológica para el diagnóstico y la planeación de infraestructura ciclista. Revista Investigaciones Geográficas, n. 91, 2016.

ANTP - Associação Nacional de Transporte Público. Sistema de Informações da Mobilidade. Relatório Comparativo 2003-2014 do SIMOB. Disponível em: http:/ / www.antp.org.br/ sistema-de-informacoes-damobilidade/apresentacao.html. Acesso em: 02 out. 2019.

ALVAREZ, Esteban King. Resenha Ciclovista Guadalajara. Descubrir la ciudad en Bicicleta. Revista Investigaciones Geográficas, n.77, p.148-150, 2012.

AASHTO - American Association of State Highway and Transportation Officials. Guide for the development of bicycle facilities. Washington, DC, 1999.

BIANCO, Sérgio Luiz. O papel da bicicleta para a mobilidade urbana e a inclusão social, 2009. Disponível em: www.ta.org.br/site/Banco/6clipping/MobilidadeSergioBianco.doc Acesso em: 02 out. 2019.

BRAGA, Alfesio; PEREIRA, Luiz Alberto Amador. Poluição Atmosférica e Saúde Humana. Revista USP, n.51, p. 58-71, 2001.

BRASIL. Secretaria Nacional de Transporte e da Mobilidade Urbana. Caderno de Referência para elaboração de Plano de Mobilidade por Bicicletas nas Cidades. Brasília, 2007.

BREITHAUPT, Manfred. Prefácio: a mobilidade urbana e a eco-mobilidade no Brasil. In: MALUF, Adalberto et al. Eco Mobilidade para o Brasil - Uma Construção Conjunta. Eschborn: Deutsche Gesellschaft fur Internationale Zusammenarbeit (GIZ), 2011. p. 1 Disponível em: https://nitbikers.files.wordpress. com/2012/01/eco-mobility-brasil.pdf Acesso em: 02 out. 2019.

CARVALHO, Mauren Lopes de; FREITAS, Carlos Machado. Pedalando em busca de alternativas saudáveis e sustentáveis. Revista Ciência e Saúde Coletiva, v.17, n.6, p. 1617-1628, 2012.

COHEN, Mirian Alfe; CASTILLO, Osvaldo Salinas. Ruido en la ciudad. Contaminación auditiva y ciudad caminable. Revista Estudios demográficos y urbanos, v. 32, n. 1, (85) p. 89-112 2017.

COMISSÃO EUROPEIA. Cidades para Bicicletas, Cidades de Futuro. Luxemburgo, 2000.

CONCEIÇÃO, Milton Luz da. O porto de Florianópolis: desenvolvimento econômico de uma ocupação estratégica. Cadernos de Arquitetura e Urbanismo, v.21, n.29, p. 105-117, 2014.

COVELLO, Cristina; HORN FILHO, Norberto; BRILHA, José. O patrimônio geológico do município de Florianópolis, Ilha de Santa Catarina, Santa Catarina, Brasil: inventário dos geossítios. Pesquisas em Geociências, v. 45, n. 1, p 1-24, 2018.

COVELLO, Cristina. O patrimônio geológico e sítios de geodiversidade do município de Florianópolis/ sc: estratégias de geoconservação. Florianópolis, 2018. Tese (Doutorado em Geografia) - Universidade Federal de Santa Catarina, UFSC.

GEIPOT. Empresa Brasileira de Planejamento de Transporte. Planejamento cicloviário: uma política para as bicicletas. Brasília, 1980.

GEIPOT. Empresa Brasileira de Planejamento de Transporte. Estudo de transporte cicloviário. Brasília, 1984.

GONDIM, Mônica Fiuza. Cadernos de desenho ciclovias. Rio de Janeiro: UFRJ/COPPE, 2010.

GORZ, André. A Ideologia Social do Automóvel. In: LUDD, Ned. Apocalipse motorizado. A tirania de um automóvel num planeta poluído. São Paulo, Conrad, 2005.

IBGE - Instituto Brasileiro de Geografia e Estatística. Pesquisa de Orçamentos Familiares 2008-2009. Despensas, orçamentos e condições de vida. Rio de Janeiro, 2010.

IBGE - Instituto Brasileiro de Geografia e Estatística. Sinopse do censo demográfico 2010. Rio de Janeiro, 2011. 
ILLICH, Ivan. Energia e equidade. In: LUDD, Ned. Apocalipse motorizado: A tirania de um automóvel num planeta poluído. São Paulo: Conrad, 2005.

INSTITUTO DE ENERGIA E AMBIENTE. A bicicleta e a cidade. Como inserir a bicicleta na política de mobilidade urbana. São Paulo, 2010.

IPEA - Instituto de Pesquisa Econômica Aplicada. Transporte urbano e inclusão social: elementos para políticas públicas. Texto para discussão n. 960, Brasília, 2003.

IPEA - Instituto de Pesquisa Econômica Aplicada. Gastos das famílias brasileiras com transporte urbano público e privado no brasil: uma análise da POF 2003 e 2009. Brasília, 2012. (Texto para discussão, 1803).

IPEA - Instituto de Pesquisa Econômica Aplicada. Estimativa dos Custos dos Acidentes de Trânsito no Brasil com Base na Atualização Simplificada das Pesquisas Anteriores do Ipea. Brasília, 2015.

IPEA - Instituto de Pesquisa Econômica Aplicada. Cidades cicláveis: avanços e desafios das políticas cicloviárias no Brasil. Rio de Janeiro, 2017.

ITDP - Instituto de Políticas de Transporte \& Desenvolvimento. Guia de Planejamento Cicloinclusivo. Rio de Janeiro, 2017.

LEANDRO, Deleon da Silva; ANGEOLETTO, Fábio. Poluição atmosférica em cidades médias: uma proposta de avaliação para Rondonópolis-MT. Revista Espaço Acadêmico, v.17, n. 198, p. 122-130, 2017.

LIMA, Josivaldo de Souza et al. Mudanças no deslocamento para o trabalho e na atividade física da população de três municípios da região de São Paulo nos anos de 2000 e 2010. Revista Brasileira de Epidemiologia, v.20, n.2, 2017.

LOBO, Zé; ANDRADE, Victor; RODRIGUES, Juciano. Perfil do Ciclista, Rio de Janeiro, 2018. Disponível em: http://ta.org.br/perfil/ciclista18.pdf Acesso em: 02 out. 2019.

RAQUEL, Roberta. Espaço em transição: a mobilidade ciclística e os planos diretores de Florianópolis. Florianópolis, 2010. Dissertação (Mestrado em Geografia) - Universidade Federal de Santa Catarina, UFSC.

PEDRALLI, Rosângela; DIAS, Sabatha C. Caracterização sócio-histórica de seis comunidades de Florianópolis/SC: uma análise a partir da amostra Floripa. Working Papers em Linguística, v.16, n.1, p. 1-19, 2015.

RIBEIRO, Cristiene. A espacialização da distribuição dos serviços e suporte para bicicletas no município do Rio de Janeiro. Revista de Geografia e Ordenamento do Território (GOT), n.13, p. 389-407, 2018.

RUMBLE, Heather; ANGEOLETTO, Fabio; CONNOP, Stuart et al. Understanding and applying ecological principles in cities. In: LEMES DE OLIVEIRA, Francisco; MELL, Ian (Eds.). Planning Cities with Nature: Theories, Strategies and Methods. Amsterdam: Springer Nature, 2019.

SILVA, Diego Fagundes et al. Prospecção projetual para o desenvolvimento de um urbanismo ecológico: Florianópolis e o caso do rio vermelho. In: PROJETAR O PROJETO COMO INSTRUMENTO PARA A MATERIALIZAÇÃO DA ARQUITETURA: ENSINO, PESQUISA E PRÁTICA, 6, 2013, Salvador. Anais ... p. $1-20$.

SOARES, André Geraldo; et al. A bicicleta no Brasil 2015. São Paulo, 2015.

SOARES, André; GUTH, Daniel. O Brasil que pedala: a cultura da bicicleta nas cidades pequenas. Rio de Janeiro: Jaguatirica, 2018.

SOUZA, André dos Santos Baldraia. Presos no círculo, prostrados no asfalto: tensões entre o móvel e o imóvel. São Paulo, 2013. Tese (Doutorado em Geografia) - Universidade de São Paulo, USP.

STINGHEN, Juliana; PACEL, Marcel. Desafio Intermodal, visualização de dados com base no design experiencial. Curitiba, 2010. Trabalho de Conclusão de Curso (Bacharel em Design Gráfico) - Universidade Federal do Paraná, UFPR.

VALE, David Souza. A cidade e a bicicleta: uma leitura analítica. Revista Finisterra, v.51, n.103, p. 1-22, 2016. 
VAZ, Murad Jorge Mussi; PEREIRA Elson Manoel. O espaço geográfico" e o "espaço social" FlorianópolisSC. Revista Geográfica de América Central, v. 1, p. 1-11, 2011.

VIACICLO. Bacias cicloviárias: interpretação e aplicação em Florianópolis - Relatório de Pesquisa. Florianópolis, 2010. Disponível em: http:/ / viaciclo.blogspot.com/ Acesso em: 02 out. 2019.

WREG, Marcos Silveira. et al. Atlas climático da região sul do Brasil: estados do Paraná, Santa Catarina e Rio Grande do Sul. Brasília: Embrapa, 2012.

Data de submissão: 28/ fev./ 2019

Data de aceite: 15/ jul./ 2019 